\title{
Acute generalized exanthematous pustulosis from imatinib
}

\author{
Lisa W Fu' ${ }^{1 *}$, Amanda Jagdis², Jason K Lee ${ }^{2}$ \\ From Canadian Society of Allergy and Clinical Immunology Annual Scientific Meeting 2014 \\ Ottawa, ON, Canada. 23-26 October 2014
}

\section{Background}

Acute generalized exanthematous pustulosis (AGEP) is rare cutaneous drug reaction involving drug-specific $\mathrm{T}$ lymphocytes and neutrophilic inflammation. Imatinib is a tyrosine kinase inhibitor used widely in treatment of chronic myeloid leukemia (CML). Rash is a common side effect of imatinib, occurring in up to $30 \%$ of patients. However, there are only two case reports to date describing AGEP secondary to imatinib.

\section{Case presentation}

A 71-year-old woman known for chronic myeloid leukemia presented with acute onset of generalized pruritus, accompanied by small erythematous papules, and diffuse general edema affecting the face, and upper and lower extremities. The rash developed over a few hours and was associated with shortness of breath, chills, and dysuria. The rash persisted for 14 days at which point a 5 day course of prednisone was prescribed which led to improvement. Imatinib (generic) had been started 3 months earlier; was temporarily interrupted for 2-3 weeks after 1 month; then restarted 2 months prior to onset of the rash. On exam there was pitting edema to lower $2 / 3$ anterior tibia, erythematous papular generalized excoriated rash with xerosis. No blistering, sloughing of skin, target lesions, or pustules. $\mathrm{CBC}$ normal, creatinine unremarkable and urine negative for eosinophils.

Imatinib (generic) was discontinued and brand name Gleevec ${ }^{\circledR}$ was started. Two weeks later the rash recurred. Eosinophil count increased to $2.84 \times 10^{9} / \mathrm{L}$. A skin biopsy was arranged which showed parakeratosis containing neutrophils with formation of intracorneal pustules, in keeping with AGEP.

Gleevec ${ }^{\circledR}$ was discontinued and Nilotinib 400mg PO BID was substituted 2 weeks later. The rash resolved

'Department of Medicine, McGill University, Montreal, QC, Canada Full list of author information is available at the end of the article and eosinophilia decreased over the next month and has not recurred.

\section{Conclusion}

AGEP is a rare complication of imatinib therapy, and should be considered in patients who present with atypical rash on imatinib.

\section{Consent}

Written informed consent was obtained from the patient for publication of this abstract and any accompanying images. A copy of the written consent is available for review by the Editor of this journal.

\section{Authors' details}

'Department of Medicine, McGill University, Montreal, QC, Canada. ${ }^{2}$ Division of Clinical Immunology and Allergy, Department of Medicine, University of Toronto, Toronto, ON, Canada.

Published: 18 December 2014

doi:10.1186/1710-1492-10-S2-A9

Cite this article as: Fu et al:: Acute generalized exanthematous

pustulosis from imatinib. Allergy, Asthma and Clinical Immunology 2014 10(Suppl 2):A9.

Submit your next manuscript to BioMed Central and take full advantage of:

- Convenient online submission

- Thorough peer review

- No space constraints or color figure charges

- Immediate publication on acceptance

- Inclusion in PubMed, CAS, Scopus and Google Scholar

- Research which is freely available for redistribution
C Biomed Central 